\title{
Mastitis bovina por Prototheca zopfii: primer aislamiento en Chile
}

\author{
Bovine mastitis caused by Prototheca zopfii: first isolation in Chile
}

\author{
L Zaror ${ }^{\mathrm{a}, \mathbf{c}^{*}, \text { K Valenzuela }}{ }^{\mathrm{a}}$, J Kruze ${ }^{\mathrm{b}}$ \\ anstituto de Microbiología Clínica, Facultad de Medicina, Universidad Austral de Chile, Valdivia, Chile. \\ bInstituto de Microbiología, Facultad de Ciencias, Universidad Austral de Chile, Valdivia, Chile. \\ 'Escuela de Tecnología Médica, Universidad Mayor, Temuco, Chile.
}

\section{SUMMARY}

\begin{abstract}
The genus Prototheca includes unicellular achlorophyllous microalgae widely distributed in the environment, some of which could be pathogenic for human and animals. However, there is no previous report regarding these pathogenic microalgae causing infections in man or animals in Chile. Twohundred milk samples collected from 150 dairy cows with clinical mastitis were inoculated onto PIM modified medium. Prototheca spp was isolated on two consecutive occasions from one cow sampled two months apart. Direct microscopic examination of wet smears made from milk samples revealed typical Prototheca cells. Biochemical tests based on carbon source assimilation identified the organism as Prototheca zopfii. This finding represents the first isolation of this environmental alga from bovine mastitis in Chile. This could be of great importance for mastitis control programs in dairy herds as Prototheca is an uncommon mastitis pathogen that does not respond to conventional antibiotic treatment.
\end{abstract}

Palabras clave: Prototheca, mastitis bovina, prototecosis.

Key words: Prototheca, bovine mastitis, protothecosis.

\section{INTRODUCCIÓN}

La mastitis bovina es una de las principales enfermedades infecciosas del ganado lechero y, a diferencia de otras enfermedades, no se puede erradicar. La enfermedad produce cuantiosas pérdidas económicas tanto para el productor debido a una menor producción de leche, reemplazo prematuro de vientres, costo de tratamientos y eliminación de leche contaminada con antibióticos como para la industria por menor calidad de la leche y subproductos (Kruze 1998, Filippsen y col 1999, San Martín y col 2002, Huijps y col 2008).

La mastitis es una enfermedad multifactorial en la cual interactúan el huésped susceptible, el medio ambiente y los microorganismos patógenos capaces de producir infecciones intramamarias. Aunque se han descrito numerosos microorganismos que pueden producir mastitis, más del 95\% de los casos son causados por agentes contagiosos como Staphylococcus aureus y Streptococcus agalactiae, y agentes ambientales como Streptococcus uberis, Streptococcus dysgalactiae y bacterias coliformes, especialmente E. coli; el $5 \%$ restante corresponde a organismos ocasionales como Klebsiella spp, Pseudomonas aeruginosa, Corynebacterium ulcerans, Nocardia spp., hongos levaduriformes como Candida y Geotrichum, y ciertas especies de algas del género Prototheca (Philpot y Nickerson 1991, Oliver y col 2004, Sánchez 2010).

Aceptado: 20.10.2010.

* 1zaror@yahoo.es
Las algas del género Prototheca son organismos unicelulares que no poseen clorofila y se encuentran ampliamente distribuidas en el medio ambiente (Anderson y Walker 1983, Pore 1983). Algunas especies pueden producir ocasionalmente infecciones cutáneas en el hombre (Follador y col 2001). En los animales se han descrito infecciones sistémicas por este agente en perros y gatos (Stenner y col 2007) y numerosos cuadros de mastitis en bovinos (Filippsen y col 1999, Swinne y col 2002, Malinowski y col 2002). Existen cinco especies reconocidas de Prototheca, de las cuales tres son consideradas patógenas: $P$. wickerhamii (infecciones en humanos), P. zopfii y P. blaschkeae aisladas de mastitis bovina (Matsuda y Matsumoto 1992, Buzzini y col 2004, Marques y col 2008).

En los rebaños lecheros es frecuente la presentación de casos clínicos de mastitis que no responden al tratamiento y cuyo agente causal no es determinado. En consecuencia, el objetivo de este trabajo fue pesquisar la presencia de Prototheca spp. en muestras de leche de vacas con mastitis con resultados bacteriológicos negativos con los métodos convencionales de aislamiento de patógenos mamarios.

\section{MATERIAL Y MÉTODOS}

Se analizaron 200 muestras de leche de 150 vacas con mastitis clínicas provenientes de diferentes rebaños lecheros de la Región de Los Ríos y Región de Los Lagos, Chile, recibidas durante un período de seis meses en el año 2008 para examen bacteriológico de rutina en el Laboratorio de Bacteriología de COOPRINSEM Ltda., Osorno. 
En el laboratorio las muestras de leche son cultivadas de acuerdo a métodos convencionales utilizando placas de agar sangre-esculina e incubadas a $37^{\circ} \mathrm{C}$ por $24-48 \mathrm{~h}$ de acuerdo a las recomendaciones del National Mastitis Council, USA (Oliver y col 2004). Para efectos de este estudio, todas aquellas muestras que resultaron negativas al cultivo convencional se congelaron a $-18^{\circ} \mathrm{C}$ y posteriormente fueron trasladadas al Instituto de Microbiología Clínica, Facultad de Medicina, Universidad Austral de Chile, para ser cultivadas en un medio selectivo para el aislamiento de Prototheca (Prototheca Isolation Medium, PIM, modificado) (Pore 1973), compuesto de hidróxido de sodio $(0,9 \mathrm{~g} / \mathrm{L})$, sulfato de magnesio $(0,1 \mathrm{~g} / \mathrm{L}), \mathrm{K}_{2} \mathrm{HPO}_{4}$ $(0,2 \mathrm{~g} / \mathrm{L})$, sulfato de amonio $(0,3 \mathrm{~g} / \mathrm{L})$, cloruro de sodio $(0,25 \mathrm{~g} / \mathrm{L})$, glucosa $(10 \mathrm{~g} / \mathrm{L})$, clorhidrato de tiamina $(0,001 \mathrm{~g} / \mathrm{L}), 5$-fluorocitosina $(0,25 \mathrm{~g} / \mathrm{L})$, cloranfenicol $(0,05 \mathrm{~g} / \mathrm{L})$ y agar agar $(20 \mathrm{~g} / \mathrm{L})$. Se ajustó el pH a 5,05,2 , se esterilizó a 1 atm. por 20 min y se distribuyó en placas Petri estériles. Los cultivos se incubaron a $29^{\circ} \mathrm{C}$ y fueron examinados a los 5, 7 y 15 días para observar el desarrollo de colonias típicas. A partir de las colonias sospechosas en PIM se realizaron preparaciones en fresco con azul de lactofenol-Giemsa para observar la morfología celular característica de Prototheca spp. Las colonias sospechosas se subcultivaron en placas de agar Sabouraud sin antibiótico y, una vez obtenido el cultivo

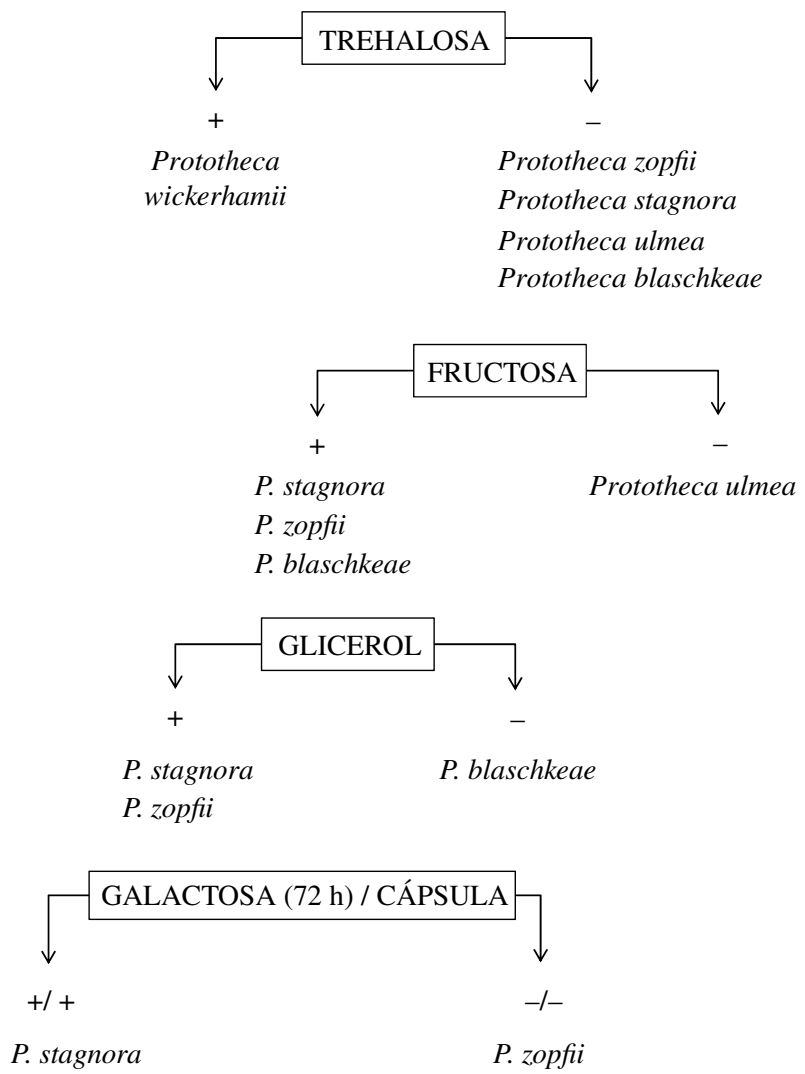

Figura 1. Clave de identificación de especies del género Prototheca.

Prototheca.

Key for the identification of species in the genus puro, las cepas fueron mantenidas a $4^{\circ} \mathrm{C}$ para su posterior identificación bioquímica. Para la identificación a nivel de especie se usó la técnica del auxanograma de fuentes de carbono, detectando la asimilación de trehalosa, fructosa, galactosa y glicerol en un periodo de cuatro días, para lo cual se diseñó una clave de identificación en base a antecedentes bibliográficos considerando la asimilación de estos hidratos de carbono y la producción de cápsula (figura 1). Simultáneamente con la siembra en PIM, se realizó un examen microscópico directo en una preparación en fresco de 50 muestras seleccionadas al azar (5 de cada 20 muestras).

\section{RESULTADOS Y DISCUSIÓN}

De las 200 muestras de leche de vacas con mastitis examinadas, sólo en dos (1\%) fue posible aislar Prototheca spp., correspondiendo ambas muestras al mismo cuarto mamario de la misma vaca muestreada con un intervalo de dos meses. En ambos cultivos en que hubo desarrollo de Prototheca spp. se observó el desarrollo de colonias blancas, de aspecto seco y con bordes irregulares (figura $2 \mathrm{~B}$ ), las que se pueden confundir fácilmente con colonias de estafilococos coagulasa negativo, razón que explicaría por qué no se detecta con mayor frecuencia en los exámenes de rutina para el diagnóstico de mastitis. El examen microscópico directo en fresco de las muestras de leche positivas al cultivo reveló la presencia de células características de Prototheca spp. (figura 2 A) y mediante la tinción con azul lactofenol-Giemsa fue posible observar la morfología característica del alga con sus tecas o esporangios en el interior (figura 3 A y B). Las dos cepas aisladas asimilaron sólo fructosa y glicerol a las $48 \mathrm{~h}$ de incubación y no presentaron cápsula, siendo identificadas como Prototheca zopfii.

El primer caso de mastitis provocada por Prototheca fue descrito en Alemania hace más de medio siglo (Lerch 1952). Posteriormente, el agente ha sido aislado de mastitis clínica y subclínica en diferentes países como Bélgica (Swinne y col 2002), Brasil (da Costa y col 1996), Canadá (Higgins y Larouche 1989), Dinamarca (Aalbaek y col 1994), Estados Unidos (Anderson y Walker 1983), Italia (Buzzini y col 2004), Japón (Furuoka y col 1989), México (Almeraya 1994), Nueva Zelanda (Hodges y col 1985), Polonia (Malinowski y col 2002), Portugal (Marquez y col 2008) y Reino Unido (Ainsworth y Austwick 1965).

En general, la mastitis por Prototheca no es una infección muy común en los animales, pero está cobrando mayor importancia en los rebaños lecheros en los cuales la prevalencia de infección por Prototheca zopfii varía entre 0,5-15\% (Jensen y col 1998, Filippsen y col 1999, Buzzini y col 2004, Bueno y col 2006). Prototheca ha sido aislado de una gran variedad de muestras ambientales incluyendo plantas, suelo, barro, charcos de agua, arroyos, agua de bebida de los animales, fecas de bovinos y porcinos, piso de las salas de ordeño y patios de estabulación (Jensen y 

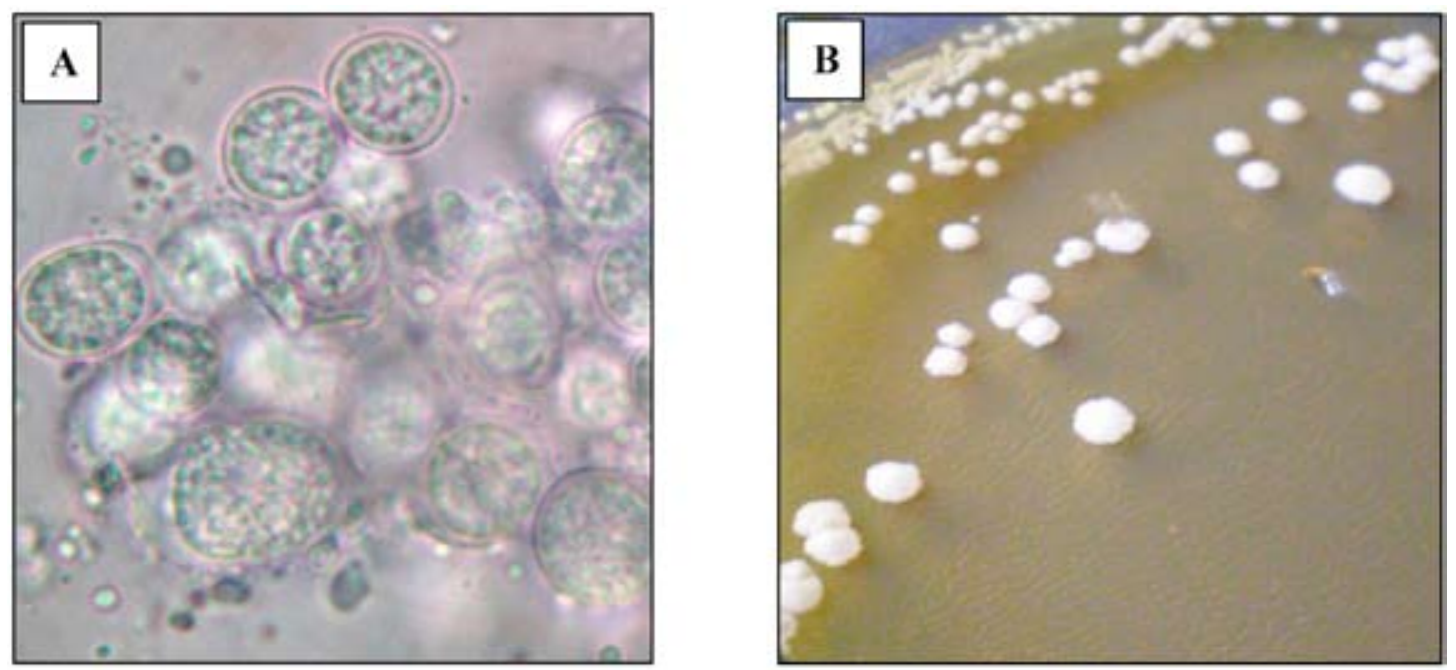

Figura 2. Examen microscópico directo (preparación en fresco) de una muestra de leche positiva a Prototheca zopfii (A) y de colonias típicas de Prototheca zopfii en PIM (B).

Microscopic appearance of Prototheca zopfii in a wet smear of milk showing sporangia containing endospores (A) and macroscopic colony appearance of Prototheca zopfii in PIM culture after 4-5 days of incubation (B).
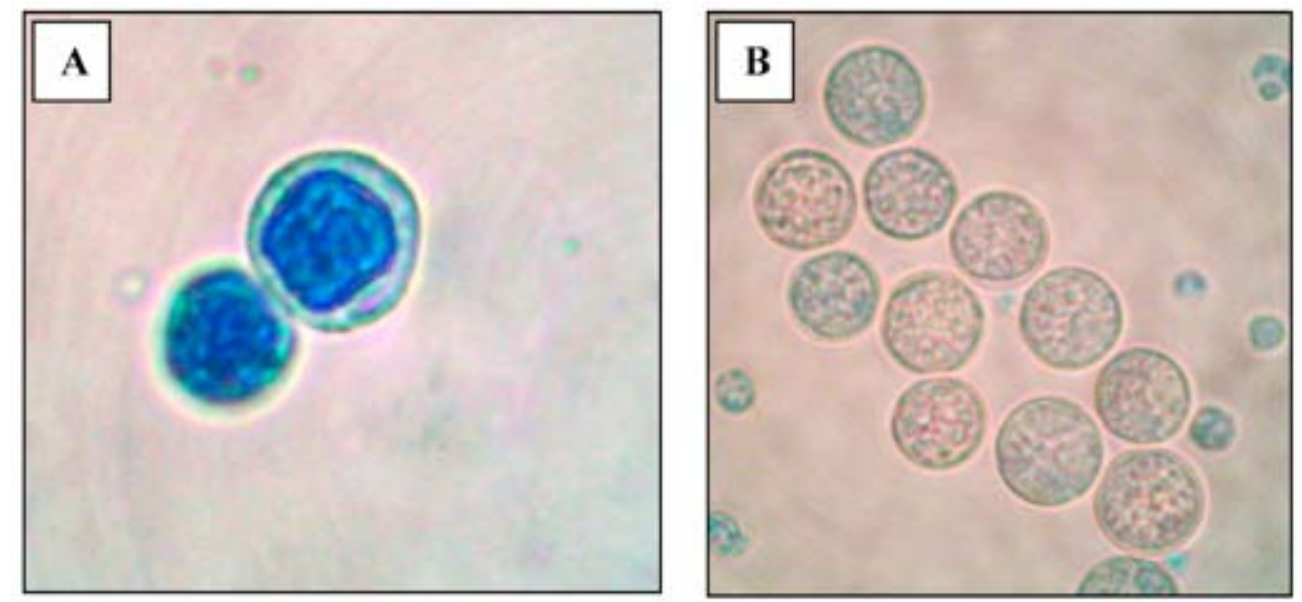

Figura 3. Células de Prototheca zopfii en diferentes estados del ciclo de vida (A y B) (Tinción azul de lactofenol-Giemsa), aumento 100x. Individual cells of Prototheca zopfii in different stages of its life cycle (Lactophenol-Giemsa stain).

col 1998, Oliver y col 2004). La distribución ubiquitaria del alga y las rutinas de ordeño deficientes, especialmente mala higiene antes de la ordeña, favorecen la infección de la glándula mamaria por vía ascendente, derivando en una mastitis crónica refractaria al tratamiento.

Prototheca zopfii es resistente a la mayoría de los antimicrobianos tradicionalmente usados en el tratamiento de mastitis, siendo ésta una las características que hacen sospechar de una infección por este agente. Ensayos realizados in vitro han demostrado que algunos antimicóticos como anfotericina B y nistatina son efectivos contra este agente, pero no son antibióticos de uso frecuente para el tratamiento de mastitis y son de alto costo, siendo la medida más práctica y efectiva eliminar los animales infectados para evitar la propagación de la infección al resto del rebaño (Almeraya 1994, Marquez y col 2006).
Cabe señalar que este hallazgo constituye el primer caso registrado de mastitis bovina por Prototheca zopfii en Chile, lo cual es relevante, además, porque permite orientar el diagnóstico en aquellos casos de mastitis que son refractarios al tratamiento o en los cuales no es posible aislar un patógeno mamario tradicional con los protocolos de cultivos de rutina. El diagnóstico oportuno y correcto de estos casos de mastitis permite adoptar las medidas adecuadas de manejo para evitar la diseminación de la infección y las posibles pérdidas económicas para el productor y la industria. Es importante tener presente que, aunque Prototheca spp. ocasionalmente causa infecciones dérmicas en humanos, puede producir infecciones intestinales y prototecosis diseminada en pacientes inmunodeprimidos (Torres y col 2003), por lo que debe tenerse presente especialmente en el área de dermatología. 


\section{RESUMEN}

El género Prototheca está formado por microalgas unicelulares sin clorofila, ampliamente distribuidas en el medio ambiente, algunas de las cuales pueden ser patógenas para el hombre y animales. Sin embargo, no existen antecedentes bibliográficos previos sobre la existencia de estas algas patógenas para el hombre y animales en Chile. Se examinó bacteriológicamente un total de 200 muestras de leche provenientes de 150 vacas lecheras con mastitis clínica, las cuales fueron sembradas en medio PIM modificado, selectivo para Prototheca. Se aisló Prototheca spp. en dos ocasiones consecutivas de una misma vaca muestreada con un intervalo de dos meses. El examen microscópico directo de las muestras de leche en fresco reveló la presencia células características de Prototheca spp. Mediante asimilación de fuentes de carbono se identificó la especie como $P$. zopfii, constituyendo el primer aislamiento de este agente a partir de un cuadro de mastitis clínica bovina en Chile. Este hallazgo es relevante para los programas de control de mastitis bovina en los rebaños lecheros ya que es un organismo poco frecuente y desconocido que no responde a los tratamientos antibióticos convencionales.

\section{AGRADECIMIENTOS}

Los autores agradecen la colaboración del Laboratorio de Bacteriología de la Cooperativa Agrícola y de Servicios Ltda. (COOPRINSEM), Osorno, el cual proporcionó las muestras de leche para este estudio.

\section{REFERENCIAS}

Aalbaek B, J Stenderup, HE Jensen, J Valbak, B Nylin, A Hude. 1994. Mycotic and algal bovine mastitis in Denmark. Acta Pathol Microbiol Immunol Scand 1029, 451-456.

Ainsworth GC, PKC Austwick. 1965. A survey of animal mycoses in Britain: mycological aspects. Trans Brit Mycol Soc 38, 369-386.

Almeraya AP. 1994. Aislamento de Prototheca en un brote de mastitis bovina. Vet Mexico 25, 65-67.

Anderson KL, RL Walker. 1983. Sources of Prototheca spp in a dairy herd environment. J Am Vet Med Ass 193, 553-556.

Bueno VFF, AJ Mesquita, RB Neves, MA Souza, AR Ribeiro, ES Nicolau, AN Oliveira. 2006. Epidemiological and clinical aspects of the first outbreak of bovine mastitis caused by Prototheca zopfii in Goiás State, Brazil. Mycophatol 161, 141-145.

Buzzini P, B Turchetii, R Facelli, R Baudino, F Cavarero, L Mattalia, P Mosso, A Martini. 2004. First large-scale isolation of Prototheca zopfii from milk produced by dairy herds in Italy. Mycopathol 158, 427-430

Da Costa EO, AR Ribeiro, PA Melville, M Prada, AC Carciofi, ET Watanabe. 1996. Bovine mastitis due to algae of the genus Prototheca. Mycopathol 133, 85-88.

Filippsen LF, FB Moreira, AT Sakashita, DR Bittencourt. 1999. Prevalence of bovine mastitis due to Prototheca zopfii in dairy cattle in north Paraná, Brazil. Ciência Rural, Santa María 29, 87-89.
Follador I, A Bittencourt, F Durán, MG Araújo. 2001. Case report. Cutaneous protothecosis: report of the second Brazilian case. Rev Inst Med Trop S Paulo 43, 287-290.

Furuoka H, A Anri, Y Arita, N Tuzuki, H Satoh, C Itakura. 1989. Protothecal mastitis in a cow. Jap J Vet Sci 51, 197-199.

Higgins R, Y Larouche. 1989. Isolation and identification of Prototheca, an agent of bovine mastitis. Med Vet Quebec 19, 140-141.

Hodges RT, JTS Holland, FJA Neilson, NM Wallace. 1985. Prototheca zopfii mastitis in a herd of dairy cows. New Zeal Vet J 33, 108-111.

Huijps K, TJGM Lam, H Hogeveen. 2008. Costs of mastitis: Focuss and perception. J Dairy Res 75, 113-120.

Jensen HE, B Aalbaek, B Bloch, A Huda. 1998. Bovine mammary protothecosis due to Prototheca zopfii. Med Mycol 36, 89-95.

Kruze J. 1998. La rutina de ordeño y su rol en los programas de control de mastitis bovina. Arch Med Vet 30, 7-16.

Lerch M. 1952. Einen durch Algen (Prototheca) hervorgerufene Mastitis der Kuh. Berl Münch tierärztl Wschr 65, 64-69.

Malinowski E, H Lassa, A Klossowska. 2002. Isolation of Prototheca zopfii from inflamed secretion of udders. Bull Vet Inst Pulawy 46, 295-299.

Marques, S, E Silva, J Carvalheira, G Thompson. 2006. In vitro antimicrobial susceptibility of Prototheca wickerhamii and Prototheca zopfii isolated from bovine mastitis. J Dairy Sci 89, 4202-4204.

Marques S, E Silva, C Kraft, J Carvalheira, A Videira, VAR Huss, G Thompson. 2008. Bovine Mastitis Associated with Prototheca blaschkeae. J Clin Microbiol 46, 1941-1945.

Matsuda T, T Matsumoto. 1992. Protothecosis: a report of two cases in Japan and a review of the literature. Eur J Epidemiol 8, 397-406.

Oliver SP, RN González, JS Hogan, BM Jayarao, WE Owens. 2004. Microbiological Procedures for the Diagnosis of Bovine Udder Infection and Determination of Milk Quality. $4^{\text {th }}$ ed. National Mastitis Council, Verona, USA.

Philpot N, S Nickerson. 1991. Mastitis Counter Attack: a strategy to combat mastitis. Babson Bros. Co., Naperville, IL, USA.

Pore RS. 1973. Selective medium for the isolation of Prototheca. Appl Microbiol 26, 648-649.

Pore RS. 1983. Prototheca ecology. Mycopathol 81, 49-62.

Sánchez N. 2010. Asociación entre niveles de células somáticas en leche de estanque y la incidencia de mastitis clínica en rebaños lecheros del sur de Chile (Región de Los Ríos). Tesis M.Sc., Facultad de Ciencias, Universidad Austral de Chile, Valdivia, Chile.

San Martín B, J Kruze, MA Morales, H Agüero, B León, S Espinoza, D Iragüen, J Puga, C Borie. 2002. Resistencia bacteriana en cepas patógenas aisladas de mastitis en vacas lecheras de la V Región, Región Metropolitana y X Región, Chile. Arch Med Vet 34, 221-234.

Stenner VJ, B Mackay, T King, VRD Barrs, P Irwin, L Abraham, N Swift, N Langer, M Bernays, E Hampson, P Martin, MB Krokenberger, K Bosward, M Latter, R Malik. 2007. Protothecosis in 17 Australian dogs and a review of the canine literature. Med Mycol 45, 249-266.

Swinne D, D Moubamba, PE Lagneau, S Geerts. 2002. Nouveaux cas d'infections par Prototheca zopfii chez la vache laitière en Belgique. Ann Méd Vét 146, 311-315.

Torres HA, GP Bodey, JJ Tarrana, DP Kontoyiannis. 2003. Protothecosis in patient with cancer: case series and literature review. Clin Microbiol Infect 9, 786-792. 